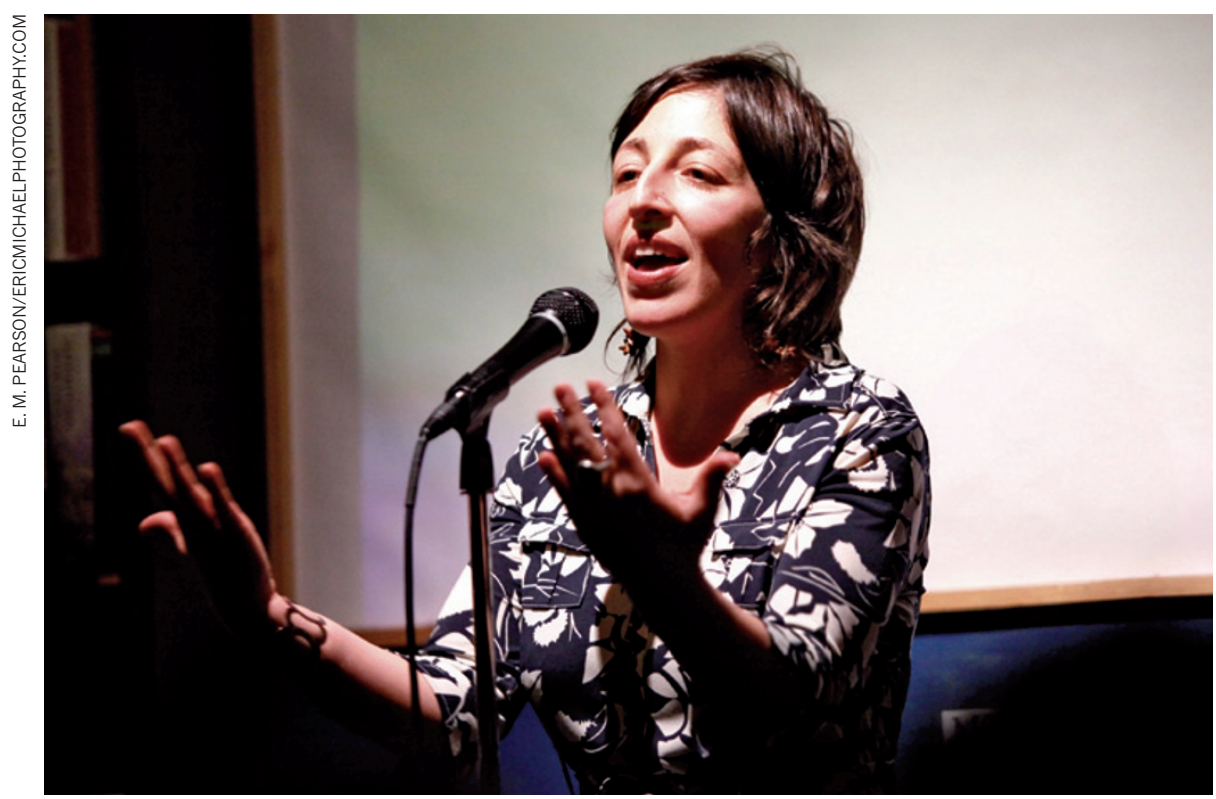

At a Story Collider show, Naomi Azar relates how her brain disorder stops her from recognizing faces.

COMMUNICATION

\title{
Show and tell
}

\section{A New York storytelling project reveals the personal side of scientific life, finds David Carmel.}

\section{$\mathrm{T}$} he man behind the microphone is clearly nervous. He is a neuroscientist, but this is not a conference or lecture. He is telling a deeply personal story at The Story Collider, a monthly New York event that has been gaining popularity for the past year, and which attracts a diverse audience to hear stories about science.

On 13 April, The Story Collider joins forces with the Zora Art Space in Brooklyn to produce a special event and exhibition of art, science and storytelling titled The Cambrian Explosion. On the opening night, four contemporary artists and two curators will tell stories about how science has influenced their work and touched their lives. Their work - paintings, photographs and sculptures - will then be exhibited until 28 April. "This will be an energetic show," promises co-curator Eric LoPresti, "dissecting neuroscience, biology, psychology and evolution through smart, visually stunning artwork."

Artists Karen Margolis and Elizabeth Demaray have undergraduate degrees in cognitive science. Margolis will show maps and 'architectural renderings' that portray emotional states and mental operations, which she created using a soldering iron to burn intricate patterns resembling neural networks into layers of pigmented paper. Sculptor Demaray will install her Lunch Box Project, which invites audience members
The Cambrian Explosion
Zora Art Space, New York. 13-28 April 2011 http://storycollider.org

to contribute food scraps to a population of 3,000 earthworms housed in a large, clear-plastic vitrine, creating a time-based 'painting' in which leftovers produce nutrient-rich soil.

Joining Margolis and Demaray are photographer Lori Nix, who will present pictures of elaborate constructed scenes - an extension of her solo show in Chicago in February, which featured a future city emptied of its human inhabitants - and painter Kysa Johnson. Johnson will exhibit monochromatic chalk drawings of luscious American landscapes, which on close inspection reveal themselves to be composed not of rivers and foliage, but of depictions of the molecular structures of the environmental pollutants ethane, benzene and acrolein.

Conversations between science and the arts are notoriously difficult. They are often hampered by the incompatibility of academic discourse on the two sides. "The idea behind this show", says co-curator and physics $\mathrm{PhD}$ Ben Lillie, "is that letting the artists tell their stories of how science has affected them can be a grounding point - a more directly human way of starting the conversation."

This is The Story Collider's first foray into bridging art and science. In the future, Lillie plans to do the opposite show, with scientists telling stories about how art has influenced their research. Lillie co-founded The Story Collider with Brian Wecht, a postdoctoral physicist at the University of Michigan in Ann Arbor. They were looking for a way to let people share their personal experiences of science.

There are many popular-science events in New York - Café Scientifique, The Secret Science Club and Nerd Nite, to name a few. These focus on imparting knowledge. Storytelling shows are another hugely successful cultural trend in the city, with events such as The Moth, The Liar Show and Told. The Story Collider combines both trends. "There are no lectures," says Lillie. "I want our audience to get a sense that science is a part of people's lives."

In The Story Collider's regular monthly shows, which take place at the Pacific Standard venue in Brooklyn, six performers tell stories about the part science has played in their lives, without notes or props. Each evening has a broad theme; past events have been titled 'Parallel Universes', 'Standard Deviation' and 'My Science Project'. They yield an eclectic mix of stories: Columbia University cosmologist Eugene Lim recounted his experiences on an aid trip to Haiti after last year's earthquake; comedian Dave Ritz told the audience how it felt to be accused of stealing, in what turned out to be a psychology experiment; and performer Seth Lind described living with a pacemaker.

"What I like most is that you can hear how science has affected absolutely everyone," says Lillie. "Scientists are often asked to talk about their work, but rarely about themselves."

This is not an entirely impartial review. That neuroscientist storyteller at the start of this report? That was me. February's theme was cognitive dissonance, and I told the audience how my teenage encounter with Oliver Sacks's books about fascinating neurological syndromes influenced my career choice, and how, years later, I was torn between scientific excitement and intense worry when my own father developed bizarre symptoms following a stroke.

Telling my story was nerve-racking at first, but as the minutes passed I could feel the crowd's attentiveness and sympathy, and I became more confident. Overall, the experience was incredibly cathartic, and having people come up to me afterwards and tell me how interesting and moving they found my story was as gratifying as any compliment I have ever received about my research. Storytelling is definitely a unique way to communicate the human side of scientific life.

David Carmel is at the Department of Psychology and Center for Neural Science, New York University, New York 10003, USA. e-mail:davecarmel@nyu.edu 